\title{
KAWENTENAN DRESTA SATUA BALI RING PASRAMAN WIDYA SANTHI DESA PENARUKAN BULELENG
}

\author{
Ida Ayu Eka Sinta Oktariyanti ${ }^{1}$, Ida Ayu Sukma Wirani ${ }^{1}$, I. B. Rai ${ }^{2}$ \\ Jurusan Pendidikan Bahasa Bali \\ Universitas Pendidikan Ganesha \\ Singaraja, Indonesia \\ e-mail: \{dayusinta676@ymail.co.id, sukma.wirani, bagus.rai\} \\ @undiksha.ac.id
}

\begin{abstract}
KUUB
Tetilikan puniki matetujon nlatarang; (1) kawentenan dresta satua Bali ring Pasraman, (2) tata cara ngajegang, lan (3) penampen. Wit data sajeroning tetilikan puniki inggih punika kawentenan dresta satua Bali ring pasraman Widya Santhi Desa Penarukan Buleleng. Tetilikan puniki nganggen kramaning praktiasa, kuisioner, sadu wicara, lan dokumentasi. Data tureksa sane kanggen; (1) identifikasi data; (2) reduksi data; (3) nlatarang data; lan (4) panyutetan. Pikolih tetilik kawentenan dresta satua Bali ring pasraman widya santhi Desa Penarukan Buleleng, sakadi; (1) kawentenan dresta satua Bali ring pasraman Widya Santhi Desa Penarukan Buleleng puniki becik pisan kawentenannyane, akeh alit-alit sane ngamiletin paplajahan masatua (2) tata cara ngajegang dresta masatua Bali majalaran antuk pasraman puniki inggih punika ngundang alit-alit saking SD, SMP, SMA lan selanturnyane ring wewidangan pakraman penarukan, usan nika kapupulang, kaicenin satua, kawigunan lan pentingnyane malajah masatua Bali, guru masatua becik lan ngulangunin, selanturnyane prasida katerapang olih sisia, lan (3) penampen Guru lan para sisia ring pasraman widya santhi indik satua inggih punika manut guru satua punika pinaka cerminan laksana jadma ring marcapada, manut para sisia satua punika akeh madaging paplajahan mangda iraga malaksana sane becik.
\end{abstract}

Kruna jejaton: Dresta, Satua Bali, Pasraman 


\section{ABSTRAK}

Penelitian ini bertujuan menjelaskan tentang (1) keberadaan tradisi satua Bali di pasraman, (2) tata cara melestarikan, dan (3) pendapat. Sumber data dalam penelitian ini adalah keberadaan tradisi satua Bali di pasraman widya santhi Desa Penarukan Buleleng. Penelitian ini menggunakan metode observasi, kuisioner, wawancara, dan dokumentasi. Analisis data yang digunakan (1) identifikasi data; (2) reduksi data; (3) klasifikasi data; dan (4) kesimpulan. Hasil penelitian keberadaan tradisi satua Bali di pasraman widya santhi Desa Penarukan Buleleng, antara lain: (1) keberadaan tradisi satua Bali di pasraman Widya Santhi Desa Penarukan Buleleng ini sangat bagus keberadaannya, banyak anak-anak yang menyukai pelajaran masatua (2) tata cara melestarikan tradisi mesatua Bali melalui pasraman ini adalah mengundang anak-anak dari jenjang SD, SMP, SMA dan sederajat di sekitaran pakraman Penarukan, setelah itu dikumpulkan, diberikan satua, kegunaan dan pentingnya belajar masatua Bali, guru bercerita dengan baik dan menarik, setelah itu anak-anak lalu menerapkannya, (3) pendapat Guru dan siswa di pasraman widya santhi tentang satua adalah menurut guru satua itu seperti cerminan perilaku manusia di dunia, menurut para siswa satua itu banyak berisi pelajaran supaya kita berprilaku yang baik.

Kata kunci: tradisi, Satua Bali, Pasraman

\section{ABSTRACT}

This study aims to explain about (1) the existence of satua Bali tradition in pasraman, (2) preservation procedure, and (3) opinion. Sources of data in this study is the existence of the tradition of satua Bali in pasraman Widya Santhi Desa Penarukan Buleleng. This research uses observation method, questionnaire, interview, and documentation. Analysis of data used (1) identification of data; (2) data reduction; (3) data classification; and (4) conclusions. Result of research of existence of tradition of satua Bali in pasraman widya santhi Desa Penarukan Buleleng, among others: (1) existence of satua Bali tradition in pasraman Widya Santhi Desa Penarukan Buleleng is very good existence, many children who love masatua lesson (2) the tradition of mesatua Bali through this pasraman is to invite children from elementary, junior high and senior level around pakraman Penarukan, then collected, given satua, the usefulness and importance of study masatua Bali, the teacher told the story well and interesting, (3) Teacher's and students' opinion in pasraman widya santhi about satua is according to the teacher of the parent is like a reflection of human behavior in the world, according to the students of the satua contains many lessons so that we will behave well.

Keywords: tradition, Satua Bali, Pasraman

\section{PURWAKA}

Basa, sastra lan aksara Bali dahat mapaiketan sareng dresta ring kauripan parajana Bali. Nika mawinang, ring Bali pemerintah dahat ngutamayang basa Bali, sane mangkin sampun prasida kacingak pembinaan basa Bali malarapan antuk wentennyane penyuluh basa Bali ring soang-soang Desa. Kawentenan penyuluh puniki, dereng wenten ring wewidangan sane lianan, sane madue basa daerah ring Indonesia" (Suaka, 2004:36). Basa dahat mawiguna pisan ring kahuripan parajana. Mawit saking nganggen basa punika 
manusa prasida nguningayang orti sareng jadma lianan. Basa taler ngangganin seni lan budaya kerana basa lan budaya madue paiketan sane nenten prasida kapasahang, santukan samian punika wantah masikan sane prasida ngwentuk lan saling ngwangun ring kahuripan.

Kasusastraan lan kebudayaan ring kauripan parajana utamanyane ring Bali sampun kaloktah nyantos ka dura Negara. Silih sinunggil kasusastraan sane sampun lumrah kauningin inggih punika satua-satua Bali. Satua yening ring basa Indonesia kasengguh cerita dongeng. Satua pamekasnyane ring Bali sampun wenten saking dumun. Ngenenin indik kawentenan satua ring Bali, wenten makudang-kudang satua sane nglimbak nganutin sapasira sane dados pragina tur sapunapi parisolahnyane. Indike punika prasida kauningin saking makeh satua-satua, minakadi satua sane nyaritayang indik parisolah para Dewa, manusa, beburon, miwah pecampuhan manusa sareng beburon.

Kawentenan satua lan dresta masatua Bali sane mangkin sampun sayan nenten kauratiang sangkaning kawentenan teknologi sane sampun nincap. Teknologi modern kabaosang sampun ngiusin kawentenan basa lan budaya sane wenten ring Bali. Punika taler parikrama masatua sampun sayan kalempasang, santukan akehnyane lilacita sane sampun nglimbak. Akeh para anak alit, para sisia lan yowana sane seneng maplalian game ring hp android, mabalih film kartun, miwah sane lianan. Kawentenane punika sane ngawiang lali tur nenten urati kapining kawentenan dresta masatua Bali. Parindikan inucap pinaka silih sinunggil sane ngawinang dresta masatua punika sayan rered kawentenannyane.

Sajeroning kawentenan satua punika, raris ngwentuk dresta masatua ring Bali. "Pakaryan masatua puniki kalaksanayang olih I Pekak miwah rerama, sane kaicen sareng pianaknyane utawi cucunyane. Masatua puniki lumbrahnyane kalaksanayang ritatkala wengi kemanten, krana semeng ngantos sande rerama nglaksanayang pakaryan nyane, punika mawinan ring wengine wau prasida kalaksanayang masatua nuju pianaknyane jagi sirep" (Suaka, 2004:61).

Kawentenan satua lan dresta masatua Bali sane mangkin sampun sayan nenten kauratiang sangkaning kawentenan teknologi sane sampun nincap. Teknologi modern kabaosang sampun ngiusin kawentenan basa lan budaya sane wenten ring Bali. Punika taler parikrama masatua sampun sayan kalempasang, santukan akehnyane lilacita sane sampun nglimbak. Akeh para anak alit, para sisia lan yowana sane seneng maplalian game ring hp android, mabalih filmkartun, miwah sane lianan. Kawentenane punika sane ngawiang lali tur nenten urati kapining kawentenan dresta masatua Bali. Parindikan inucap pinaka silih sinunggil sane ngawinang dresta masatua punika sayan rered kawentenannyane.

Sane mangkin alit-alite merasa kimud malajahin basa Bali, napi malih ngresepang satua basa Bali. Lianan punika taler ring kaluwarga pamekasne para rerama sampun arang sane ngamargiang dresta satua Bali majeng ring pianaknyane. Para rerama ring aab jagate sekadi mangkin, galahnyane akeh kaanggen ngrereh pangupa jiwa saking semeng nyantos peteng, galahe nenten prasida yening ngicenin geginan masatua. Pikobet punika raris ngranayang pianak nyane nenten uning tekening satuasatua Bali. Punika mawinan alit-alite mangkin kabaosang krisis moral. 
Kawentenan pasraman dahat ngwantu jagi kaanggen ngentasin krisis moral punika, pamekasnyane pasraman punika ngajain alit-alite indik budaya Bali sane marupa praktik lan teori nganutin ajahan dharma sumangdane prasida nglaksanayang tri kaya parisudha ring jagate. Pasraman puniki prasida ngembasang sisia-sisia mapineh lan maparilaksana sane becik. Pasraman niki kalaksanayang sane awuku ping kalih. Puniki silih sinunggil upaya ngajegang dresta ring Bali, khususnyane Dresta Masatua Bali sane sayan rered kawentenane.

Ring penelitian puniki panilik jagi nyelehin indik kawentenan dresta satua Bali, tata cara ngajegang dresta masatua Bali lan penampen guru lan sisia ring pasraman widya santhi indik satua Bali. Antuk punika, titiang ngambil murda kawentenan dresta satua Bali ring Pasraman Widya Santhi Desa Penarukan Buleleng.

Panilik ngrereh makudangkudang pikobet sane mapaiketan sareng dadalan pikobet sane sampun kabahbahang ring ajeng. Pikobet sane sampun karereh minakadi(1) Sapunapi kawentenan dresta satua Bali ring Pasraman Widya Santhi Desa Penarukan Buleleng? (2) Sapunapi tata cara ngajegang dresta masatua Bali majalaran antuk Pasraman Widya Santi ring Desa PenarukanBuleleng? (3) Napi tetujon kawentenang pasraman Widya Santhi Desa Penarukan Buleleng? (4) Sapunapi penampen para sisia ring pasraman Widya Santi Desa Penarukan Buleleng indik satua Bali? (5) Sapunapi penampen guru ring pasraman Widya Santi Desa Penarukan Buleleng indik satua Bali? lan (6) Sapunapi guna sarat satua-satua sane kaajahin ring pasraman Widya Santhi Desa Penarukan Buleleng?
Saking nenem pikobet sane sampun katlatarang ring ajeng, panilik ngawatesin antuk tiga pikobet manten. panilik ngawatesin antuk tiga pikobet manten. Ring tetilikan puniki, kawentenan dresta, tata cara ngajegang, lan penampen guru/ para sisia ring pasraman Widya Santhi Desa Penarukan Buleleng indik satua Bali.

Bantang pikobet tetilik:(1) Sapunapi kawentenan dresta satua Bali ring Pasraman Widya Santhi Desa Penarukan Buleleng? (2) Sapunapi tata cara ngajegang dresta masatua Bali majalaran antuk Pasraman Widya Santi ring Desa Penarukan Buleleng?Lan(3) Sapunapi penampen para sisia ring pasraman Widya Santi Desa Penarukan Buleleng indik satua Bali?

Tetujon tetilik: (1) Mangda prasida uning kawentenan dresta satua Bali ring Pasraman Widya Santi Desa Pakraman Penarukan Buleleng; (2) Mangda prasida uning tata cara ngajegang dresta masatua Bali majalaran antuk Pasraman Widya Santi ring Desa enarukan Buleleng; lan(3) Mangda prasida uning penampen para sisia ring Pasraman Widya Santi indik satua Bali.

Kawigunan tetilik puniki prasida kabinayang dados kalih, inggih punika kawigunan pamucuk miwah kawigunan panglimbak. Makakalih kawigunan punika sakadi ring sor:(1) prasida ngicenin kaweruhan indik Dresta lan Budaya Bali; (2) kawigunan panglimbak sane pacang mawiguna majeng ring krama, panilik, miwah panilik lianan.

Kasusastraan inggih punika pikolih saking pangawi sane ngametuang antuk basa. Manut djoko pradopo, dkk. (2013:9) sastra prasida kaanggen maosang indik gejala sane prasida kacingakin ring para krama. NglanturKuthaRatna (2009:124) maosang sastra nenten 
je pinaka napi sane kabaos lengut kemanten, nanging pinaka jangkepan sane prasida katerima olih para krama, sane mabinaan, sakadi tata titi miwah adat istiadat.

$$
\text { Manut ring aab nyane }
$$

kasusastraan Bali kakepah dados

kalih soroh inggih punika

kasusastraan Bali Purwa lan Bali

Anyar. Kasusastraan Bali Purwa punika kasusastraan sane sampun katami saking riin gumanti sampun leket ring kayun parajanane, taler leket ring pustaka suci Agama Hindu. Kasusastraan Bali Purwa punika kawangun antuk tigang pahan, inggih punika tembang (puisi), gancaran (prosa),lan palawakya. Kasusastraan Bali Anyar inggih punika kasusastraan Bali sane metu saking pawerdian lan lelimbakan kasusastraan nasional. Kasusastraan Bali Anyar akeh pisan wangun nyane sakadi satua bawak, novel, puisi lan drama.

Kasusastraan Bali inggih punika saluir pangweruh sane medal saking pikayunan para sujana sane marupa ajah-ajahan, tutur-tutur sane luhing utama, sane nganggen basa Bali lan kawi tur kasurat ngangge aksara Bali lan latin sane katami rauh mangkin. Taler wenten kasusastraan sane nenten kasurat sane kabaos sastra tutur (lisan) sakadi satua miwah sane tiosan.

Sastra lisan inggih punika kasusastraan sane nglingkupin kawentenan semita utawi ekspresi kasusastraan krama ring sajeroning budaya sane kawedar secara nglantur kapungkur wekas kawentenan sastra lisan punika (saking cangkem ring cangkem sane tiosan)(Astika, 2014: 2). Manut Suwardi (2011: 1999) nguningayang wigunan saking sastra lisan utamannyane prasida kakepah dados papat, inggih punika didaktif, pinaka panglipur lara, pinaka wentuk penampen miwah sastra lisan kaanggen dados sasindiran. Ceciren sastra lisan inggih punika sekadi tata cara ngawedar lan ngalimbakangnyane, kolektif, anonym, tradisional, madue makudang versi, madue wiguna ring sajeroning paguyupan krama, madue wentuk utawi pola miwah madue pola sastra.

Satua inggih punika silih sinunggil wangun kria sastra Bali sane marupa papalihan saking sastra gancaran. Kamus Besar Bahasa Indonesia (KBBI) nlatarang satua inggih punika carita sane nyritayang indik kejadian ring zaman sane sampun lami, kejadiannyane punika durung pastika kawentenannyane.

Antara (2006 :1) ngimbuhin satua inggih punika wangun carita sane wenten ring kauripan krama Bali lan sampun kauningin saking lami tur nenten wenten wasta sang sane nyurat lan nenten kauningin warsa carita punika kakawi.

Sudjana (2005: 83) maosang carita utawi prosa krama sane kaparcayain yakti kawentenannyane, terutaman ipun kaanggen hiburan yadiastun akeh sane ngambarang kejatian saking carita punika, madaging paplajahan moral utawi sindiran.

Manut sekadi Tinggen (2001: 20) maosang satua inggih punika pupulan makudang-kudang lengkara sane nyaritayang kauripan saking witnyane nyantos puput. Dados katingkesan satua inggih punika wangun carita sane wenten ring kauripan krama Bali sane marupa carita fantasi utawi khayalan sane nenten kauningin keyaktiyannyane, nanging satua puniki sampun kauningin daweg dumun tur nenten wenten wasta pawanginyane lan warsa karya sastra puniki kakawi.

Manut Tinggen (2001: 14) maosang satua Bali madue ceciren inggih punika : Wastan saking pangawinyane nenten kasurat (anonym), Inti saking carita 
dadosnyane karereh untengnyane sane marupa makna tersirat, Nganggen lengkara pamungkah sakadi "ade kone tuturan satua", miwah Nganggen kruna "lantas laut",Yening wenten kata sambung ring carita, kata sambung sane kaanggen punika "maan".

Antara (2011:45) maosang Satua sane sampun nglimbak ring krama Bali prasida kabinayang manut soroh caritanyane inggih punika fabel, mite, legenda, sage, miwah lelucon.

Manut praginanyane wenten pepitu sorohan pragina, Antara (2011: 73) inggih punika Pragina buron sareng buron, Pragina manusa sareng beburon, Pragina manusa sareng manusa, Pragina manusa, buron, lan raksasa, Pragina bhatara sareng manusa, Pragina Bhatara, manusa lan buron, miwah Pragina bhatara lan beburon.

Antara (2006: 25) maosang satua madue kawigunan sakadi Numbuhang sesawangan (imajinasi) lan reragragan (daya fantasi anak), Nglimbakang parisolah sane urati (kritis) lan jemet (kreatif), Prasida minayang parisolah sane becik lan sane patut katulad, miwah Madue rasa bakti lan andel ring padewekan muah solah sane becik majeng ring para anome.

Suastika (2011: 20) maosang ring paplajahan satua Bali punika sisia prasida uning ring sajeroning kawigunan satua pinaka tatuladan ring kahuripan sekadi kawigunan ring kahanan pendidikan, kawigunan ring kahanan religius, kawigunan ring kahanan sosial, miwah kawigunan ring kahanan bebanyolan.

Suksman utawi teges mapaiketan sareng pralambang, inggih punika maosang inggian parindikan sane becik, nilai sane kaerasang olih kramane pinaka parindikan sane dahat mabuat miwah madue nilai positif ring kahuripan. ManutSuastika (2011: 33) suksman tradisi lisan (satua) punika wenten 5 , inggih punika suksman pemersatu, suksman kontrol sosial, suksman religius, miwah suksman bebanyolan.

Ring sajeroning mababaosan, miarsayang kaangkenin pinaka kawikanan komunikasi verbal sane dahat meweh pisan yening saihang antuk komunikasi verbal sane tiosan, sekadi mababaosan, nyurat, ngawacen saantukan dahat akedik pisan sane prasida nglaksanayang saha becik. Miarsayang wantah sinalih tunggil kawagedan mabasa sane prasida kadruenang. Bilih-bilih saking makasami kawagedan mabasa, miarsayang prasida kapikayunin pinaka pabinayan sane pinih ageng. Amunapi ja becik utawi luihnyane iraga miarsayang, punika madue pikolih sane ageng sareng pamargin pakaryan iraga lan kabecikan paiketan iraga sareng jatma tiosan. Pamitutur sane becik lan antar pacang mikolihang kapiambeng yening nenten prasida miarsayang saha becik.

Dudonan ring sajeroning miarsayang inggih punika katerima utawi pikolih, kauningang/ kawagedan miarsayang, pangelingeling, nureksain miwah penampen. Soroh-soroh miarsayang wenten tetiga inggih punika miarsayang secara pasif, miarsayang secara kritis, lan miarsayang secara aktif.

\section{KRAMANING TETILIK}

Yening kacingak ring
tatujonnyane, tetilikan punika
matetujon nelatarang indik data sane
sampun kapolihang. Untengnyane,
tetilikan puniki nganggen palihan
tetilikan deskriptif utamanyane
nganggen kramaning deskriptif kualitatif. Wenten lelima papalih paridabdab kramaning tetilik sakadi: (1) pendekatanlansoroh tetilik; 
Tetilik puniki ngangge pendekatan lan soroh tetilik deskriptif kualitatif; (2) Genah tetilikan puniki ring Pasraman Widya Santhi Desa Penarukan Buleleng; (3) Wit data sajeroning tetilikan puniki inggih punika dresta satua Bali ring Pasraman Widya Santhi Desa Penarukan Buleleng; (4) mupulang data, Kramaning kanggen mupulang data inggih punika kramaning kramaning praktiasa (observasi), kuisioner, sadu wicara (wawancara) lan dokumentasi, piranti sane kanggen mupulang data inggih punika kuisioner; lan (5) data tureksa, Pamargin data tureksa sane kalaksanayang ring sajeroning tetilikan puniki inggih punika a) identifikasi data b) reduksi data c) klasifikasi data d) panyutetan.

\section{PIKOLIH LAN TETEPASAN}

Pikolih lan tetepasan kawentenan dresta satua Bali ring pasraman widya santhi Desa Penarukan Buleleng katlatarang ring sor puniki.

Satua pamekasnyane ring Bali sampun wenten saking dumun. Ngeninin indik kawentenan satua ring Pasraman puniki, wenten makudang-kudang satua sane nglimbak nganutin sapasira sane dados pragina tur sapunapi parisolahnyane ring satua. Indike punika prasida kauningin olih para sisia ring pasraman punika, minakadi satua sane nyaritayang indik parisolah para Dewa, manusa, beburon, miwah pecampuhan manusa sareng beburon sane wenten ring caritanyane. Satua sane nganggen beburon pinaka pragina ring satua sekadi sane sampun lumrah kauningin.

Pasraman puniki magenah ring wewidangan Desa Pakraman Penarukan Buleleng, pasraman puniki kamargiang ping kalih sane awuku ring rahina saniscara galah
16.00-17.30 sore lan redite galah 08.00-10.00 semeng. Akeh paplajahan sane kaajahin ring pasraman puniki, luirnyane makarya piranti persembahyangan, nyurat aksara Bali (nyastra) lan masatua Bali.

Wantah 15 satua Bali sane kauningin, krana ring pasraman punika Jero Dalang Paneca ngajahin satua sane lumrah lan sane dangan karesepang olih alit-alit. Yening selehin, satua akeh madue kawigunan sane becik santukan prasida kaanggen sarana paajahajah anggen ngwangun parisolah anak alit.

Ring pasraman puniki parasisia nenten kaharusang mangda prasida bisa masatua. Sane penting nika alitalit prasida nguningin indik kawentenan satua lan dresta satua Bali punika. Parikrama puniki kamargiang pinaka wentuk rasa rungu ring pidabdab ngajegang nilai budaya tetamian leluhur, nguningayang tetuek sane wenten ring carita punika, ngantos bebanyolan taler kacaritayang.

Puniki pacang katelatarang Unteng sane wenten ring satua, kawigunan sane wenten ring satua, lan arti/ suksman sane wenten ring satua, sane kauningin olih sisia-sisia sane wenten ring pasraman widya santhi Desa Penarukan Buleleng. Saking satua kapertama kantos satua kaping untat sekadi ring sor puniki.

Satua I Siap Selem, manut Ida Ayu Catur Oka Febriani (11 tiban) sinalih tunggil sisia sane wenten ring pasraman uning unteng sane wenten ring satua I Siap Selem inggih punika Daya Upaya (Akal Cerdik), kawigunan sane wenten ring satua I Siap Selem inggih punika kawigunan ring kahanan bebanyolan, lan suksman sane wenten ring satua I Siap Selem inggih punika suksman pemersatu, lan suksman bebanyolan. 
Satua I Bawang teken I Kasuna, Manut Putu Wahyuni Putri Utami (11 Tiban) sinalih tunggil sisia sane wenten ring pasraman uning unteng sane wenten ring satua I Bawang teken I Kasuna inggih punika Satya ngawi bagya, kawigunan sane wenten ring satua I Bawang teken I Kasuna inggih punika kawigunan ring kahanan pendidikan, lan suksman sane wenten ring satua I Bawang teken I Kesuna inggih punika suksman kesejahteraan lan suksman kontrol sosial.

Satua I Lutung teken I Kakua, Manut Dewa Kadek Oka Wedana (10 tiban) sinalih tunggil sisia sane wenten ring pasraman uning unteng sane wenten ring satua I Lutung teken I Kakua inggih punika Daya Upaya (Akal Cerdik), kawigunan sane wenten ring satua I Lutung teken I Kakua inggih punika kawigunan ring kahanan religius, lan suksman sane wenten ring satua I Lutung teken I Kakua inggih punika suksman kontrol sosial lan suksman religius.

Satua Men Tiwas teken Men Sugih, Manut Desak Dian (10 tiban) sinalih tunggil sisia sane wenten ring pasraman uning unteng sane wenten ring satua Men Tiwas teken Men Sugih inggih punika ngukuhang padewekan (pengendalian diri) miwah pikayun, ) kawigunan sane wenten ring satua Men Tiwas teken Men Sugih inggih punika kawigunan ring kahanan pendidikan, kawigunan ring kahanan religius,lan kawigunan ring kahanan sosial, lan suksman sane wenten ring satua Men Sugih teken Men Tiwas inggih punika suksman kontrol sosial lan suksman kesejahteraan.

Satua Ni Tuung Kuning, Manut Dewa Putu Satria Wiguna (13 tiban) sinalih tunggil sisia sane wenten ring pasraman uning unteng sane wenten ring satua $\mathrm{Ni}$ Tuung Kuning inggih punika Karma Phala, kawigunan sane wenten ring satua
$\mathrm{Ni}$ Tuung Kuning inggih punika kawigunan ring kahanan religius, lan suksman sane wenten ring satua I Siap Selem inggih punika suksman religius.

Satua I Angsa teken I Empas, Manut Desak Komang Sri Yantini (11 tiban) sinalih tunggil sisia sane wenten ring pasraman uning unteng I Angsa teken I Empas inggih punika Ngukuhang padewekan miwah pikayun, kawigunan sane wenten ring satua I Angsa teken I Empas inggih punika kawigunan ring kahanan sosial lan suksman sane wenten ring satua I Angsa teken I Empas inggih punika suksman kontrol sosial.

Satua I Kambing ajak I Lutung, Manut Dewa Kadek Witara (11 tiban) sinalih tunggil sisia sane wenten ring pasraman uning unteng I Kambing teken I Lutung inggih punika Daya Upaya (Akal Cerdik), kawigunan sane wenten ring satua I Kambing ajak I Bojog inggih punika kawigunan ring kahanan bebanyolan, lan suksman sane wenten ring satua I Kambing ajak I Lutung inggih punika suksman bebanyolan.

Satua Pan Balang Tamak, Manut Dewa Putu Krisna Dana (13 tiban) sinalih tunggil sisia sane wenten ring pasraman uning unteng sane wenten ring satua Pan Balang Tamak inggih punika Daya Upaya (Akal Cerdik), kawigunan sane wenten ring satua Pan Balang Tamak inggih punika kawigunan ring kahanan sosial lan kawigunan ring kahanan bebanyolan lan suksman sane wenten ring satua Pan Balang Tamak inggih punika suksman pemersatu, lan suksman bebanyolan.

Satua Sang Prabu Aji Dharma, Manut Dewa Kadek Leo Putra (13 tiban) sinalih tunggil sisia sane wenten ring pasraman uning unteng sane wenten ring satua Sang Prabhu Aji Dharma inggih punika 
paritutur sane sujati utawi parilaksana sane luwih, kawigunan sane wenten ring satua Sang Prabu Aji Dharma inggih punika kawigunan ring kahanan religius, lan suksman sane wenten ring satua Sang Prabu Aji Dharma inggih punika suksman religius.

Satua I Tuma teken I Titih, Manut Ida Ayu Indah Trisnawati (11 tiban) sinalih tunggil sisia sane wenten ring pasraman uning unteng sane wenten ring satua I Tuma teken I Titih inggih punika lobha ngawi sengkala, kawigunan sane wenten ring satua I Tuma teken I Titih inggih punika kawigunan ring kahanan pendidikan, lan suksman sane wenten ring satua I Tuma teken I Titih inggih punika suksman kontrol sosial.

Satua I Belog, Manut Dewa Putu Wahyu Ardi Putra (13 tiban) sinalih tunggil sisia sane wenten ring pasraman uning unteng sane wenten ring satua I Belog inggih punika kabelogan, kawigunan sane wenten ring satua I Belog inggih punika kawigunan ring kahanan bebanyolan, lan suksman sane wenten ring satua I Belog inggih punika suksman bebanyolan.

Satua Kambing takutin Macan, Manut Reshnya Graciella Sahertian (10 tiban) sinalih tunggil sisia sane wenten ring pasraman uning unteng sane wenten ring satua Kambing takutin Macan inggih punika Daya Upaya (Akal Cerdik), kawigunan sane wenten ring satua Kambing takutin Macan inggih punika kawigunan ring kahanan bebanyolan, lan suksman sane wenten ring satua Kambing takutin Macan inggih punika suksman pemersatu, lan suksman bebanyolan.

Satua Nang Cubling, Manut Gusti Ayu Agung Tania Gautami (11 tiban) sinalih tunggil sisia sane wenten ring pasraman uning unteng sane wenten ring satua Nang
Cubling inggih punika Daya Upaya (Akal Cerdik), kawigunan sane wenten ring satua Nang Cubling inggih punika kawigunan ring kahanan bebanyolan, lan suksman sane wenten ring satua Nang Cubling inggih punika suksman pemersatu, lan suksman bebanyolan.

Satua Rare Angon, Manut Desak Ketut Ari Suastini (11 tiban) sinalih tunggil sisia sane wenten ring pasraman uning unteng sane wenten ring satua Rare Angon inggih punika paritutur sane sujati utawi parilaksana sane luwih, kawigunan sane wenten ring satua Rare Angon inggih punika kawigunan ring kahanan pendidikan, lan suksman sane wenten ring satua I Siap Selem inggih punika suksman religius lan suksman kesejahteraan.

Satua I Ubuh, Manut Desak Kadek Merry Sukmawati (11 tiban) sinalih tunggil sisia sane wenten ring pasraman uning unteng sane wenten ring satua I Ubuh inggih punika paritutur sane sujati utawi parilaksana sane luwih, kawigunan sane wenten ring satua I Ubuh inggih punika kawigunan ring kahanan pendidikan, lan suksman sane wenten ring satua I Ubuh inggih punika suksman Kontrol sosial.

Ngajegang dresta masatua Bali majalaran antuk pasraman puniki dahat mawiguna pesan, krana prasida ngelestariang dresta satua ring Bali. Masatua punika wantah tata cara sane becik pacang ngawentuk sifat anak alit. Anak alit prasida nureksain lan uning ring parilaksana sane becik lan nenten becik.Tata cara ngajegang dresta masatua Bali majalaran antuk pasraman puniki inggih punika sane kapertama, kaundang alit-alit sane saking jenjang SD, SMP, SMA miwah selanturnyane ring pantaraning wewidangan Desa pakraman Penarukan, derika lantas 
kapupulang alit-alit sane ngamiletin pasraman punika. Kaping kalih, yening sampun mapupul derika lantas alit-alit kaicenin paplajahan masatua, kawigunan lan pentingnyane malajah masatua Bali. usan nika lantas kaicenin satuasatua sane kabaktayang saha becik. Guru masatua alit-alit mirengang utawi miarsayang saha becik, usan nika sane kaping untat alit-alit kaicen galah masatua ke arep timpaltimpalne, guru membimbing alit-alit mangda prasida maktayang satua saha becik.

Penampen Guru Jero Dalang Paneca indik satua punika inggih punikia satua nika dumun kalaksanayang olih lingsir-lingsire sadereng sirep oka-okane. Tetujon ipun gumanti ngicenin pratiwimbapratiwimba majeng ring oka-okane. Satua punika pinaka cerminan laksana jadma ring mercapada.

Selanturnyane

penampen saking ali-alit ring pasraman puniki indik satua inggih punika, satua nika becik pisan, punika akeh medaging paplajahan sane becik, satua nika mengajarkan mangda iraga melaksana sane becik, prasida ngajahin yening melaksana becik, melah tepukin. Yening melaksana kaon, sengkala sane jagi iraga tepukin. Satua puniki mangda prasida katerusang ring pasraman puniki.

Manut sekadi penampen ring ajeng, prasida karingkesan satua punika wangun carita sane wenten ring kauripan krama Bali sane marupa carita fantasi utawi khayalan sane nenten kauningin keyaktiyannyane, nanging satua puniki sampun kauningin daweg dumun tur nenten wenten wasta pawanginyane lan warsa karya sastra puniki kakawi.

Panyutetan indik pikolih tetilikan sane sampun kalaksanayang inggih punika Kawentenan dresta satua Bali ring pasraman Widya Santhi
Desa Penarukan Buleleng puniki sanget becik . akeh alit-alit sane seneng ngamiletin paplajahan masatua lan akeh sane sampun uning indik satua-satua Bali punika. Alit-alit masih prasida uning indik tatuek satua, kawigunan satua, miwah suksman satua.

Tata cara ngajegang dresta masatua Bali majalaran antuk Widya Santhi ring Desa Penarukan Buleleng inggih punika kaundang alit-alit sane saking jenjang SD, SMP, SMA miwah selanturnyane ring wewidangan Desa Pakraman Penarukan.

Penampen Guru lan para sisia ring pasraman Widya Santhi Desa Penarukan Buleleng indik satua inggih punika manut Guru Jero Dalang Paneca Satua punika pinaka cerminan laksana jadma ring mercapada. Satua punika luire sumberne subha lan asubha karma nika tujuan anak lingsir makarya satua mangda wenten anggena pedoman ring sajeroning malaksana ring jagate. Yening manut alit-alit satua punika akeh medaging paplajahan sane becik, satua nika mengajarkan mangda iraga melaksana sane becik, prasida ngajahin yening melaksana becik, melah tepukin. Yening melaksana kaon, sengkala sane jagi iraga tepukin.

\section{PAMUPUT}

Ring tetilikan puniki durung wenten tetilikan sane asoroh, puniki wantah tetilikan anyar. Malarapan antuk tetilikan sane sampun kapolihang lan katepasin olih panilik indik kawentenan dresta masatua Bali ring Pasraman Widya Santhi Desa Penarukan Buleleng, tetilikan puniki madue kaluihan minakadi panilik prasida nilikin indik kawentenan dresta masatua Bali ring Pasraman, ngamolihang 15 
satua sane kauningin olih alit-alit ring pasraman punika, ring satua-satua punika alit-alit prasida nguningayang piteket, unteng, kawigunan lan suksman saking satua punika. Taler prasida nguningin tata cara ngajegang dresta masatua Bali majalaran antuk pasraman punika lan uning penampen-penampen saking guru miwah sisia ring pasraman punika indik satua Bali. Kakirangannyane punika sisia-sisia saking pasraman Widya Santhi puniki durung nanin nyarengin pacentokan masatua. Sapatutnyane sisia ring pasraman sane sampun waged masatua, yening wenten pacentokan masatua ring wewidangan Penarukan utawi ring genah sane tiosan, sumangdana para sisia punika sareng ngamiletin pacentokan. Mangda paplajahan masatua sane kapolihang ring pasraman punika mawiguna.

Piteket kawedarang majeng ring: (1) majeng ring alit-alit ring pasraman, mangda sayan teleb nglanturang paplajahan sane kaajahin ring pasraman punika, mangda prasida melahirkan generasi muda hindu sane becik; (2) Majeng ring alit-alit lan para yowana, mangda nyelehin malih dagingdaging satua Bali, Majeng ring parajana sane durung makulawarga, mangda becik pikayunanne maurukin utawi malajahin satuasatua Bali punika mangdane benjangan ritatkala sampun makulawarga, prasida raris nglimabakang ring pianaknyane, miwah Majeng ring parajana sane sampun makulawarga, mangdane nenten waneh-waneh ngicen paplajahan lan masatua sane katah madaging piteket-piteket gumanti prasida kaanggen titi ritatkala maparisolah utawi malaksana sakantune maurip ; (3) Majengring panilik sios, sumangdane prasida nglaksanayang panilikan selanturnyane majalaran antuk tetilikan sane tios tur instrument sane kaanggen mangda kakaryanang sane dangan; (4) Majeng ring sang sane ngwacen, yening manawi wenten kakirangkirangannyane mangda prasida ngicen piteket ring panilik, sumangdane benjangan skripsi puniki prasida paripurna.

\section{KAPUSTAKAAN}

Anandakusuma, Sri Reshi. 1986. Kamus Bahasa Bali. Graha Pengaratan: CV. Kayumas Agung.

Antara, I Gusti Putu.2011. Teori Apresiasi Sastra Bali Anyar.Singaraja: Yayasan Saba Sastra Bali.

Arikunto, Suharsini.2005.Manajemen Penelitian.Jakarta: Rineka Cipta.

-----.2006.Prosedur Penelitian Suatu Pendekatan Praktik.Jakarta: Rineka Cipta.

Astika, Yasa. 2014. Sastra Lisan Teori dan Penerapannya. Yogyakarta: Graha Ilmu.

Djoko Pradopo, Rachmat. 2003. Metodologi Penelitian Sastra. Yogyakarta: PT Anindita Graha Widya.

Esten,mursal.1999.Desentralisasi Kebudayaan.Bandung: Angkasa.

Gautama, Wayan Budha.2007.Kasusastraan Bali.Cakepan Panuntun Malajahin Kasusastraan Bali. Surabaya: Paramita

Hermawan, Herry. 2012. Menyimak Keterampilan Berkomunikasi yang Terabaikan. Yogyakarta: Graha IImu.

lqbal, Hasan. 2002. Pokok-Pokok Materi Metodologi Penelitian dan Apliasinya. Indonesia: Ghalia

Kutha Ratna, Nyoman. 200. Teori, Metode, dan Teknik Penelitian 
Sastra dari Strukturalisme

Hingga Postrukturalisme

Perspektif Wacana Naratif.

Yogyakarta: Pustaka Pelajar.

Suaka, I Nyoman.2004.Dinamika

Kasusastraan Indonesia.Balai

Bahasa Pusat Bahasa

Departemen Pendidikan

Nasional Denpasar.

Suandi, Nengah. 2008. Pengantar Metodologi Penelitian Bahasa.

Singaraja: Undiksha.

Suastika, I Made. 2011. Tradisi Sastra Lisan (Satua) di Bali. Denpasar:Pustaka Larasan

Sudjana, H.D. 2005. Strategi Pembelajaran. Bandung: Fatah Produktion.

Sugiyono. 2013. Metode Penelitian Kuantitatif, Kualitatif, dan R\&D. Bandung: Alfabeta.

Tinggen, I Nengah. 2001. Kumpulan Buku Satua. Singaraja: Universitas Pendidikan Ganesha

Wendra, I Wayan. 2014. Buku Ajar Penulisan Karya IImiah. Singaraja: UNDIKSHA 